\title{
Mathematical Physical Diagnosis of Fetal Cardiotocography Based On Probability and The S / K Ratio of Entropy
}

\author{
Javier Rodríguez ${ }^{1}$, Jaime Paez ${ }^{2}$ \\ ${ }^{1}$ Insight Group Director, Insight Research Group SAS, Bogotá, Colombia. \\ ${ }^{2}$ Grupo NEOTIC. Universidad Cooperativa de Colombia, seccional Bogotá. Bogotá, \\ Colombia.
}

\begin{abstract}
Introduction: Intrapartum fetal status surveillance methods must be capable of detecting fetuses in a situation of developing short- and long-term complications, in order to carry out medical or surgical interventions that attempt to improve their perinatal outcome.

Objective: to confirm the reproducibility and clinical applicability of a mathematical diagnosis based on probability and entropy, designed to evaluate normal and abnormal cardiotocographic tracing for 20 minutes in the context of dynamic systems theory.

Methodology: For this, 80 cardiotocographic tracings were taken divided into two groups of normal and with loss of fetal well-being. The frequency of appearance of each heart rate presented in discrete time intervals was calculated from the probability and the ratio between the entropy value and Boltzmann's constant (S / k). Subsequently, the mathematical diagnosis was applied to make distinctions between normal fetal cardiac dynamics of patients.

Results: the values of the entropy $\mathrm{S} / \mathrm{k}$ proportions obtained when evaluating the cardiotocographic tracings differentiated normal fetal cardiac dynamics from patients.

Conclusion: The 20-minute normal and abnormal cardiotocography tracings were correctly evaluated from the values of the entropy $S / k$ ratio and the previously established diagnostic parameters, thus confirming their clinical applicability.
\end{abstract}

Key Words: probability, fetal heart rate, cardiotocography. 


\section{Introduction}

In physics, an experiment subject to an $\mathrm{n}$ number of times the toss of a coin has only two chances of landing, therefore it generates two events that can take integer values within a finite number of possibilities $(1,2)$. In probability theory, the relationship between the frequency distribution of these two events and their probability is called the probability distribution (3). In the context of quantum mechanics, the quantity of particles that are distributed in a certain discrete energy level that are differentiated by their probability distributions (3). In the kinetic theory of gases, the entropy law is stated as the number of possible states in the context of equiprobable systems. This law was later generalized within the framework of statistical mechanics, achieving its application in out-of-equilibrium systems (4-6). For non-equiprobable systems, entropy is evaluated through the Boltzmann-Gibbs equation (4), which in the context of the information theory proposed by Claude Shannon maintains its mathematical expression (7).

The World Health Organization in 2018 estimated that 2.5 million children worldwide died in the first month of life. Additionally, there are approximately 7000 newborn deaths that are reported each day (8). The risk of death of a child is highest during the neonatal period (1). Perinatal death is established when it occurs between the 28th week of gestation and the seventh day of birth. Monitoring fetal well-being during pregnancy, labor, and delivery are considered key components in optimizing fetal outcomes (9). Cardiotocography (CTG) records continuously and for 20 minutes the fetal heart rate (FHR) obtained through an ultrasound transducer placed on the mother's abdomen $(9,10)$. The FCF is part of the indicators of fetal well-being, which can be evaluated through CTG records during the antepartum period as well as intrapartum. In this record, the initial frequency, initial variability, accelerations and decelerations can be evaluated (10).

In clinical practice, the use of CTG in pregnancy is based on the fact that it is a test that allows the detection and identification of babies with acute or chronic fetal hypoxia or at risk of developing this condition $(9,10)$. Additionally, evidence-based studies conclude that fetal hypoxia produces specific pathophysiological adaptations in the fetus, which can cause changes in the pattern of FHR parameters (10). At the time of interpreting an abnormal CTG tracing, it may require additional diagnostic tests, which avoid hospital admission prematurely, as well as induction of labor with or without caesarean section (9-11). To minimize the short- and longterm risks that caesarean sections represent for the mother and the child, studies have been conducted that analyze the association between the number of caesarean sections and continuous intrapartum fetal monitoring with the CTG that is not adequately interpreted (11) .

Given these results, new investigations have been proposed from the field of theoretical mathematics and physics, to develop diagnostic methodologies that evaluate CTG tracings (1217). Among them is a methodology based on probability theory and the relationship between entropy and Boltzmann's constant (S / k), in the context of the Boltzmann-Gibbs entropy law (13), which has been shown to be of useful for identifying situations that are associated with the Risk of Loss of Fetal Well-being (RPBF), determining ranges of normality, disease and 
evolution between these states. The purpose of this study is to apply this methodology (13) in a greater number of CTG tracings to confirm its reproducibility and clinical applicability of the methodology compared to conventional clinical evaluation (13).

\section{Methods}

\section{Definitions}

Probability of the fetal heart rate: corresponds to the number of times in which the maximum and minimum values of the FHR appear in 10-second intervals, divided by the total of times that the maximum and minimum values of the FHR appeared during the entire CTG trace .

$P_{n}=\frac{\text { Heart rate repetitions }}{\text { Total cardiac repetitions in the entire record }}$ Equation 1

Entropy of the CTG trace is evaluated with the following equation:

$$
S=-k \sum_{n=0}^{N} P_{n} \ln \left(P_{n}\right)
$$

\section{Equation 2}

Being S the value of the entropy, $\mathrm{k}$ the Boltzmann constant which value is $1.38 \times 10-23$ Joules / kelvin, $\mathrm{Pn}$ is the $\mathrm{n}$-th probability value that was evaluated with equation 1 .

S / $\mathbf{k}$ ratio: it is the result of the algebraic clearing of the constant $\mathrm{k}$ of equation 2 , to leave it in terms of the $S / \mathrm{k}$ ratio.

$$
S / k=-\sum_{n=0}^{N} P_{n} \ln \left(P_{n}\right)
$$




\section{Population}

80 CTG tracings were taken from the archives of the Insight group and the San Luis de Bucaramanga Clinic. Pregnant patients older than 21 years were admitted to the gynecology service with and without any obstetric pathology that influenced fetal well-being. The CTG tracings of these patients were evaluated by a specialist in gynecology and obstetrics during the last trimester, according to the parameters of the bulletin of the American College of Obstetricians and Gynecologists (ACOG), clinical management guidelines for obstetricsgynecology (18).

\section{Procedure}

The clinical conclusion of each CTG tracing was masked by the specialist. Next, the maximum and minimum value of the FCF was noted and systematized for each tracing in 10-second intervals. Then the number of times these values were repeated during the 20 minute traces was quantified, to later evaluate the probability with equation 1 in each of these traces. The probability distributions found by not presenting an equiprobable distribution, for each of the selected CTG tracings, their entropy was evaluated with equation 2 and the S / k relationship with equation 3. Finally, the previously developed diagnostic evaluation parameters were applied. (13), based on probability and S / k relationships, looking for equalities or differences.

\section{Statistical Methodology}

Subsequently, the clinical conclusions were unmasked to be compared with the physicalmathematical evaluation. The clinical conclusions include the normal interpretation of the CTG tracings, which were taken as Gold Standard, for this specificity, sensitivity, negative predictive value (NPV) and positive (PPV) were calculated, the calculation of these values was carried out by means of a classification binary where the true positives (VP) are the number of fetal cardiac recordings with conventional and abnormal physical-mathematical evaluation, the false positives (FP) correspond to the number of fetal cardiac tracings whose physical-mathematical evaluation is abnormal but the conventional one was normal. false negatives (FN) correspond to the number of fetal cardiac recordings associated with an abnormal conventional diagnosis, with normal mathematical values; and finally the true negatives (VN) correspond to the fetal heart traces mathematically diagnosed as normal and in the same way with the conventional diagnosis. Also, the Kappa coefficient was evaluated.

\section{Ethical aspects}


This research complies with the ethical principles for medical research in human beings of the Declaration of Helsinki of the World Medical Association, in general terms with the ethical, scientific, technical and administrative standards for health research, based on the resolution No. 008430 of 1993, and specifically with title 11 referring to research in human beings, as it is classified in the category of research without risk, since physical calculations are made on the results of non-invasive examinations of clinical practice, protecting the integrity and anonymity of the participants.

\section{Results}

The probability distributions of the frequency of occurrence of the maximum and minimum values of the FCF of all the CTG traces ranged between 0 and 0.525 . The probability distributions of the CTG traces evaluated as reactive varied between 0 and 0.375 , the nonreactive traces varied between 0 and 0.525 .

The values of the entropy $\mathrm{S} / \mathrm{k}$ ratio for each of the probability distributions of the FCF ranged between -2.315 and -1.278 . The values of the $S / k$ ratio ranged between -1.941 and -1.717 , for the reactive CTG traces, between -2.315 and -1.278 for the non-reactive CTG traces

In the analysis of diagnostic concordance between the mathematical physical diagnosis and the conventional clinical evaluation, sensitivity and specificity values of $100 \%$ and a Kappa coefficient of one were found.

\section{Discussion}

This is the first study that confirms the clinical applicability of a diagnostic methodology based on probability, entropy and the entropy $\mathrm{S} / \mathrm{k}$ ratio, to evaluate normal and abnormal FCF values from cardiotocography tracings, in the context of a blinded study. The methodology once again showed its ability to differentiate normal from abnormal FHR, including episodes of bradycardia and tachycardia, based on the values of the entropy $\mathrm{S} / \mathrm{k}$ ratio, also establishing a special range for evolution between normality and disease., of clinical importance at the preventive level. Additionally, the range of values of the entropy $\mathrm{S} / \mathrm{k}$ relationship, for which the loss of fetal well-being is established, allows within a general group to discriminate subgroups of patients at perinatal risk, additionally, it focuses attention on cases of greater clinical risk, this methodology being very useful for making clinical decisions.

In the current medical literature, there are studies in which the lack of uniform criteria for the patterns of normality and abnormality established for FCF (19-22) is discussed, in the guidelines designed by the International Federation of Gynecology and Obstetrics ( FIGO) and the (ACOG). Instead, this research shows how a methodology that previously established mathematical parameters and diagnoses of normality and abnormality, as well as the evolution towards one of these two states, can be reproducible, which implies a significant decrease in subjectivity in the interpretations of cardiotocography. . 
Currently, inter and intra observation for the interpretation of CTG tracings is still a matter of discussion $(19,21)$. In a study conducted with six physicians with more than five years of experience in the obstetric service, they were asked to evaluate the basic characteristics of CTG tracings, including baseline, variability, accelerations and decelerations, sinusoidal pattern. , tachysystole and classify each scan as normal, suspicious or pathological, according to the FIGO 2015 guidelines on intrapartum fetal monitoring (21). The results of the study reveal that, although there is good inter-observer agreement in the evaluation of most of the CTG characteristics, there is no agreement in the interpretation of bradycardia, reduced variability, the jumping pattern, the absence of accelerations and decelerations. (twenty-one). In contrast, in a study carried out with nine obstetricians who were asked to review 360 CTG recordings, each with an approximate duration of 60 minutes, no agreement was found between the characteristics of the CTG and whether a discharge inherent variability between and within observers (22).

For its part, the application of physical and mathematical theories for the evaluation of fetal cardiac physiology, such as the one applied in this study, allows, through the values of the S / $\mathrm{k}$ ratios, to evaluate all fetal cardiac dynamics and differentiate normality of disease and evolution between these. Additionally, the methodology makes it possible to evaluate chronic diseases, their evolution, show cases in a state of exacerbation, and also evaluate tachycardias, bradycardias, failed attempts to induce labor and Loss of Fetal Well-being (RPBF). The precision of the methodology to evaluate the behavior of the FCF of the CTG tracings is due to the underlying mathematical characteristics of the mathematical physical diagnosis, established from mathematical patterns that characterize normality and establish how far away a fetal cardiac dynamics is. of normality, undoubtedly within the mathematical characteristics of the disease (13). The clinical reproducibility of this diagnostic methodology was confirmed in two studies, the first carried out on 25 CTG traces and the second on 40 CTG traces $(14,15)$. Additionally, the methodology showed the possibility of evaluating the FCF from the CTG traces of 15 minutes duration (16).

The application of the theory of probability and entropy has allowed the study of other phenomena achieving predictions and diagnoses in different areas of medicine, such as studies carried out in fields such as immunology and molecular biology, cardiology, public health, among others (23-26). Like the methodology applied in the present work, these works obey an acausal understanding of the phenomena of medicine, which reveal underlying mathematical orders.

\section{Conflicts of interest}

The authors declare that they have no conflicts of interest.

\section{Funding}


This article is the result of the INV2811 project financed by the Universidad Cooperativa de Colombia, Bogotá section.

\section{Acknowledgments}

The authors thank the Doctors, Fernando Colmenares, Director of Research, Leonardo Galindo, National DINAI Director, Andrés Mena, DINAI Bogotá Director, Eva Prada, Bogotá Headquarters Director, and Edgar López, Dean of the Faculty of Engineering, for their support. to our investigations.

We extend our thanks to Insight Research Group SAS for supporting our research.

\section{References}

1. Feynman RP, Leighton RB, Sands M. Probabilidad. En: Feynman RP, Leighton RB, Sands M. Física. Vol. 1. Wilmington: Addison-Wesley Iberoamericana, S. A. 1964; p. 61, 6-16.

2. Laplace P. Ensayo filosófico sobre las probabilidades. Barcelona: Altaya 1995.

3. Chernega V, Man'ko O, Man'ko V. Probability Representation of Quantum Observables and Quantum States. Journal of Russian Laser Research. 2017; 38(4):324-333.

4. Matvéev A. Física molecular. Primera edición, Moscú: MIR, 1987.

5. Tolman R. Principles of statistical mechanics. Primeraedición. New York: Dover Publications. 1979.

6. Mood A, Graybill F, Boes D. Introduction to the theory of statistics. 3a Ed. Singapore Mc. Graw-Hill. 1974.

7. Machta J. Entropy, information, and computation. Am. J. Phys. 1999; 67: 1074 - 7.

8. Organización Mundial de la Salud. Recién nacidos: reducción de la mortalidad. Disponible en: https://www.who.int/en/news-room/fact-sheets/detail/newborns-reducing-mortality

9. Devane D, Lalor JG, Daly S, McGuire W, Cuthbert A, Smith V. Cardiotocography versus intermittent auscultation of fetal heart on admission to labour ward for assessment of fetal wellbeing. Cochrane Database Syst Rev. 2017;1(1):CD005122. Published 2017 Jan 26. doi:10.1002/14651858.CD005122.pub5

10. Grivell RM, Alfirevic Z, Gyte GM, Devane D. Antenatal cardiotocography for fetal assessment. Cochrane Database Syst Rev. 2015;2015(9):CD007863. Published 2015 Sep 12. doi:10.1002/14651858.CD007863.pub4.

11. Turnbull D, Salter A, Simpson B, et al. Comparing the effect of STan (cardiotocographic electronic fetal monitoring (CTG) plus analysis of the ST segment of the fetal electrocardiogram) with CTG alone on emergency caesarean section rates: study protocol for the STan Australian Randomised controlled Trial (START). Trials. 2019;20(1):539. Published 2019 Aug 29. doi:10.1186/s13063-019-3640-9

12. Rodríguez J, Prieto S, Ortiz L, Bautista A, Bernal P, Avilán N. Diagnóstico Matemático de la monitoria fetal aplicando la ley de Zipf-Mandelbrot. Rev Fac Med Univ Nac Colomb. 
2006; 54(2):96-107.

13. Rodríguez J. Nuevo diagnóstico físico y matemático de la monitoria fetal: predicción de aplicación clínica. Momento Revista de Física. 2012; 44: 49-65.

14. Soracipa Y, Rodríguez J, Castillo M. Confirmación diagnóstica de la evaluación del trazado de la monitoria fetal a partir de la probabilidad y la relación S/k de la entropía. Momento. 2018; 57:27-40.

15. Rodríguez J, Castillo M, Cuevas R. Diagnóstico matemático del trazado de la monitoria fetal fundamentado en la relación S/k de la entropía. Arch Med Manizales. 2017;17(1):2737.

16. Rodríguez J, Castillo M, Restrepo O, Correa C, Cuevas R, Trejos C. Evaluación en 15 minutos del monitoreo fetal fundamentada en la probabilidad y la proporción S/k. Revista Cubana de obstetricia y Ginecología. 2019; 45(2):1-11.

17. Rodríguez J, Prieto S, Correa C. Evaluación diagnóstica de la dinámica cardiaca caótica fetal a partir de la evolución del sistema dinámico. Pren. Med. Argent. 2019;105(3):110118.

18. Antepartum Fetal Surveillance. Obstet Gynecol. 2014 Jul;124(1):182-92.

19. Sholapurkar SL. Critical Imperative for the Reform of British Interpretation of Fetal Heart Rate Decelerations: Analysis of FIGO and NICE Guidelines, Post-Truth Foundations, Cognitive Fallacies, Myths and Occam's Razor. J Clin Med Res. 2017;9(4):253-265. doi:10.14740/jocmr2877e.

20. Olofsson P, Norén H, Carlsson A. New FIGO and Swedish intrapartum cardiotocography classification systems incorporated in the fetal ECG ST analysis (STAN) interpretation algorithm: agreements and discrepancies in cardiotocography classification and evaluation of significant ST events. Acta Obstet Gynecol Scand. 2018;97(2):219-228. doi:10.1111/aogs. 13277

21. Rei M, Tavares S, Pinto P, et al. Interobserver agreement in CTG interpretation using the 2015 FIGO guidelines for intrapartum fetal monitoring. Eur J Obstet Gynecol Reprod Biol. 2016;205:27-31. doi:10.1016/j.ejogrb.2016.08.017

22. Spilka J, Chudáček V, Janků P, Hruban L, Burša M, Huptych M, Zach L, Lhotská L. Analysis of obstetricians' decision making on CTG recordings. J Biomed Inform. 2014;51:72-79. doi:10.1016/j.jbi.2014.04.010

23. Rodríguez J, Bernal P, Álvarez L, Pabón S, Ibáñez S, Chapuel N, et al. Predicción de unión de péptidos de MSP-1 y EBA-140 de plasmodium falciparum al HLA clase II Probabilidad, combinatoria y entropía aplicadas a secuencias peptídicas. Inmunología. 2010; 29(3):9199.

24. Rodríguez J, Prieto S, Ramírez L. A novel heart rate atractor for the prediction of cardiovascular disease. Informatics in medicine. 2019; 15(100174):1-9.

25. Rodríguez J. Método para la predicción de la dinámica temporal de la malaria en los municipios de Colombia. Rev Panam Salud Pública 2010; 27(3):211-218.

26. Rodríguez J, Prieto S, Pérez C, Correa C, Soracipa Y, Jattin J, David A. Predicción temporal de CD4+ en 80 pacientes con manejo antirretroviral a partir de valores de leucocitos. Infectio. 2020;24(2):103-107. 